\title{
Significado para o paciente egresso da unidade de terapia intensiva sobre a assistência recebida por acadêmicos de enfermagem
}

\author{
Oyara de Castro*, Lígia Vieira Tenório Sales, M. Sc. ${ }^{* *}$
}

*Enfermeira, Aluna do Curso de Especialização em Urgência, Emergência e Terapia Intensiva da Escola de Enfermagem Wenceslau Braz, ItajubálMG e Docente da referida instituição, ${ }^{* *}$ Professora Orientadora da Escola de Enfermagem Wenceslau Braz, ItajubálMG

\section{Resumo}

Estudo de abordagem qualitativa, do tipo transversal que teve como objetivo conhecer o significado para o paciente egresso da unidade de terapia intensiva (UTI) de um hospital escola sobre assistência recebida por acadêmicos de enfermagem. A amostra constou de 20 pacientes egressos da UTI internados nas clínicas médica e cirúrgica. A amostragem foi do tipo proposital. Os dados coletados foram descritos sob o referencial das Representaçôes Sociais, utilizando o Discurso do Sujeito Coletivo (DSC) como método para a construção dos significados da pesquisa, o que permitiu a aproximação com o fenômeno do estudo. Os resultados revelaram que todos os pacientes reconheceram a dedicaçáo e a qualidade da assistência prestada pelo acadêmico de enfermagem. Evidenciou-se que a atuação dos acadêmicos na UTI oportunizou a troca de conhecimentos e experiências com a equipe de enfermagem desta unidade contribuindo para a qualidade da assistência de enfermagem prestada.

Palavras-chave: unidades de terapia intensiva, cuidados de enfermagem, assistência ao paciente.

\section{Abstract \\ Meaning of care given by nursing academics to patients egressed from Intensive Care Unity}

This study used a qualitative approach, transversal type, aiming at knowing the meaning of care given by nursing academics to patient egressed from Intensive Care Unit (ICU) of a Hospital School. Twenty (20) patients who had egressed from the $\mathrm{UCI}$ and were admitted in the medical and surgical clinics composed the sample. It is a purposeful sampling. Collected data was described under the Social Representation referential, by using the Collective Subject Discourse (CSD) as the method of construction of meanings, which make possible to approximate to the studied phenomenon. Results showed that all patients recognized the dedication and the quality of care provided by the nursing academic. It has been made evident that academics performance in ITU provided an opportunity for exchange knowledge and experience between the nursing team of this unity and patients, contributing to nursing care quality.

Key-words: intensive care unit, nursing care, patient care. 


\section{Resumen}

\section{Significado para el paciente egreso de la unidad de cuidados intensivos sobre la atención brindada por académicos de enfermería}

Estudio de abordaje cualitativo del tipo transversal que tuvo como objetivo conocer el significado para el paciente egreso de la unidad de cuidados intensivos (UCI) de un hospital escuela sobre la asistencia recibida por académicos de enfermería. Participaron del estudio 20 pacientes egresos de la UCI internados en las clínicas médicas y quirúrgicas. El muestreo fue propositivo. Los datos recogidos fueron descritos bajo el referencial de las Representaciones Sociales, utilizando el Discurso del Sujeto Colectivo (DSC) como método para la construcción de significados de la investigación, lo que permitió la aproximación con el fenómeno del estudio. Los resultados revelaron que todos los pacientes reconocieron la dedicación y la calidad de atención brindada por los académicos de enfermería. Se comprobó que la actuación de los académicos en la UTI promovió el intercambio de conocimientos y experiencias con el equipo de enfermería de esta unidad, contribuyendo para la cualidad del cuidado brindada por el personal de enfermería.

Palabras-clave: unidad de cuidados intensivos, atención de enfermería, atención al paciente.

\section{Introdução}

A Unidade de Terapia Intensiva (UTI) é um setor criado com o objetivo de prestar assistência de alta complexidade a pacientes críticos e recuperáveis [1]. Essa assistência é de suma importância, pois possibilita avaliar a qualidade não somente dos profissionais, mas também da instituição hospitalar [2]. A equipe de enfermagem ao prestar cuidados aos pacientes em UTI convive diariamente com o sofrimento, com a morte e realiza procedimentos técnicos de alta complexidade para a manutençáo da vida [3].

$\mathrm{O}$ acadêmico de enfermagem na UTI depara-se muitas vezes com profissionais médicos e enfermeiros, que se posicionam frente a eles com indiferença, impaciência e principalmente com colocaçóes do tipo: "tal paciente náo quer que o aluno cuide dele", "o paciente reclamou dos cuidados recebidos pelo aluno”. Comentários desta natureza traduzem o cuidado prestado ao paciente em decepção, visto que no ensino clínico o acadêmico é acompanhado diretamente pelo docente e no estágio supervisionado há a supervisão dos professores. Outros profissionais como técnicos de enfermagem fazem observaçóes indevidas com o paciente sobre a qualidade da assistência prestada pelos acadêmicos que, mesmo em tom de brincadeira, podem induzi-lo ao receio de permitirem que estes sejam os seus cuidadores.

As colocações dos profissionais geraram inquietaçóes que foram compartilhadas entre alguns professores da Escola de Enfermagem Wenceslau Braz (EEWB) inseridos no contexto do ensino clínico e estágio supervisionado na UTI.
Diante deste contexto o presente estudo tem como objetivo: Conhecer o significado para o paciente egresso da unidade de terapia intensiva do Hospital Escola da cidade de Itajubá-MG sobre a assistência recebida por acadêmicos de enfermagem da Escola de Enfermagem Wenceslau Braz de Itajubá/MG durante o período de internação na referida unidade.

\section{Material e métodos}

Esta pesquisa foi realizada no Hospital Escola (HE) na cidade de Itajubá, Minas Gerais. O HE é campo de estágio para acadêmicos de medicina, enfermagem, fisioterapia, nutrição e residência em diversas especialidades [4].

$\mathrm{O}$ presente estudo foi de abordagem qualitativa, do tipo transversal. A abordagem qualitativa surgiu na antropologia, uma vez que os pesquisadores não conseguiam explicar, pelo método quantitativo, o modo de viver das pessoas. Determinados problemas de pesquisa não podem ser respondidos quantitativamente, porque não se busca estabelecer relaçōes entre variáveis ou verificar empiricamente hipóteses. Quando existe a intenção de buscar significados e interpretá-los a partir de um contexto próprio, natural, delineia-se a abordagem qualitativa do estudo [5].

Os estudos transversais são aqueles em que a coleta de dados é feita em um determinado tempo, nos quais os dados relacionados às variáveis independentes e dependentes são coletados simultaneamente [6]. 
Teve como participantes os pacientes egressos da UTI do Hospital Escola de Itajubá. A amostra foi constituída de 20 participantes e a amostragem do tipo proposital.

Os critérios de inclusão adotados para este estudo foram: ter sido paciente egresso da UTI do HE de Itajubá-MG; internado na clínica médica ou cirúrgica desta instituição de saúde; ter sido cuidado por acadêmicos de enfermagem da Escola de Enfermagem Wenceslau Braz de Itajubá/MG independente de ser do $5^{\circ}, 6^{\circ}, 7^{\circ}$ ou $8^{\circ}$ períodos por no mínimo três dias, considerando este período como o mínimo para melhor interação do paciente na unidade; ter estado consciente, auto, alo e crono orientado no período que foi cuidado por acadêmicos de enfermagem na UTI e durante a coleta de dados na clínica médica ou cirúrgica; ser paciente atendido pelo Sistema Único de Saúde (SUS), tendo em vista que a instituição onde foi realizada a pesquisa náo autoriza que alunos, independentemente do curso, prestem assistência aos pacientes internados que possuam outros tipos de convênio médico, seja ele particular ou empresarial; ter idade acima de 18 anos; que concordaram em participar do estudo.

Para a coleta de dados elaborou-se um questionário referente às características pessoais (gênero, idade, escolaridade, profissão, religião e tempo de internação na UTI) e um roteiro de entrevista semiestruturada constituído por uma questão aberta referente ao objetivo do estudo: Você esteve internado na UTI e soube que foi cuidado por alunos de enfermagem. Fale para mim o que significou para o Sr. (Sra.) receber os cuidados por alunos de enfermagem quando esteve internado na UTI? $\mathrm{Na}$ questão do roteiro de entrevista semi-estruturado utilizou-se o termo aluno, pois acredita-se ser de melhor entendimento para o participante da pesquisa, embora em todo o trabalho esteja utilizando o termo acadêmico acreditando ser o mais adequado para se referenciar o aluno da graduação.

A coleta dos dados foi realizada pela pesquisadora no período de 2010 a 2011 nas Clínicas Médica e Cirúrgica do HE, na cidade de Itajubá. Os pacientes foram abordados respeitando os critérios de elegibilidade, informados sobre o objetivo da pesquisa, explicado que não seriam identificados, que seus relatos seriam gravados em gravador portátil, que os princípios éticos seriam resguardados e solicitou-se sua participação na mesma. Esta foi confirmada com a assinatura do participante no
Termo de Consentimento Livre e Esclarecido. Com a assinatura dos participantes deu-se início a coleta de dados em um local na unidade, respeitando a privacidade desse paciente em ambiente tranquilo e horário que melhor atendesse sua vontade e a ordem da unidade. Em seguida todos os relatos gravados foram transcritos na íntegra e posteriormente destruídos.

Os dados foram descritos sob o referencial das Representaçóes Sociais utilizando o Discurso do Sujeito Coletivo (DSC) como método para a construção dos significados, o que permitiu a aproximação com o fenômeno em estudo.

As representaçóes sociais consistem na maneira de interpretar a nossa realidade cotidiana uma forma de conhecimento social, ao associar a atividade mental desenvolvida pelos indivíduos e os grupos, para fixar sua posiçáo em relação à situação, acontecimentos, objetos e comunicação que lhes dizem respeito [7].

O DSC é uma proposta de organização e tabulação de dados qualitativos de natureza verbal, obtidos de depoimentos, artigos de jornal, matérias de revistas semanais ou especializadas, cartas, entre outras [8]. Para elaboração do DSC são criadas três figuras metodológicas: expressão-chave, ideias centrais e discurso do sujeito coletivo como segue [8]:

As expressôes chaves (ECH) são pedaços, trechos ou transcriçóes literais do discurso, que são sublinhadas, iluminadas ou coloridas pelo pesquisador, e que revelam a essência do depoimento ou, mais precisamente, do conteúdo discursivo dos segmentos em que se dividiu o depoimento, que em geral corresponde à questão de pesquisa;

As ideias centrais (IC) são nomes ou expressōes linguísticas que revelam e descrevem, da maneira mais sintética, precisa e fidedigna possível, o sentido de cada um dos discursos analisados e de cada conjunto homogêneo de ECH que irá dar nascimento, posteriormente, ao DSC;

O Discurso do Sujeito Coletivo é um discurso-síntese redigido na primeira pessoa do singular e composto pela $\mathrm{ECH}$ que tem a mesma IC.

Este estudo foi aprovado pelo Comitê de Ética em Pesquisa da Escola de Enfermagem Wenceslau Braz por meio do Parecer Consubstanciado de $n^{\circ}$ 553/2010, no dia 26/10/10 e seguiu os preceitos estabelecidos pela resolução $\mathrm{n}^{\circ}$. 196/96 do Minis- 
tério da Saúde que resguarda os Princípios Éticos para Pesquisas Envolvendo Seres Humanos. A resolução ressalta que a autonomia do participante seja preservada; haja a autorização da instituição para o desenvolvimento da pesquisa; o termo de Consentimento Livre e Esclarecido que oficializa a decisão do participante; que seja mantido o anonimato de cada depoente, de seus relatos, a guarda dos arquivos e a confidencialidade; a não identificação dos depoentes, sendo enumerados por: participante 1, 2, 3 e, assim, sucessivamente; o direito de se retirar da pesquisa a qualquer momento sem nenhum dano; a informaçáo pública dos resultados; o respeito dos valores culturais, sociais, morais, religiosos, éticos, hábitos e costumes dos participantes; as informações obtidas não foram utilizadas em prejuízo de qualquer natureza para eles.

\section{Resultados}

Em relação às características pessoais dos participantes, observou-se que, quanto ao gênero, $45 \%$ dos participantes eram do gênero feminino e $55 \%$ do gênero masculino, a idade variou de 21 anos até 86 anos, sendo que $55 \%$ dos participantes tinham idade superior a 60 anos. Em relação à escolaridade, $50 \%$ tinham ensino fundamental incompleto, $25 \%$ ensino fundamental completo, $10 \%$ ensino médio completo, $10 \%$ possuíam ensino superior e $5 \%$ dos participantes eram analfabetos. Do ponto de vista profissional, 25\% eram aposentados, $20 \%$ donas de casa, 15\% agricultores e $40 \%$ tinham profissóes variadas. Quanto à religião, $85 \%$ eram da religiáo católica e 15\% evangélicos. Constatou-se que o tempo de internação na UTI variou de 3 a 28 dias. Em relação ao motivo da internação, $50 \%$ eram pacientes em pós-operatório de vários tipos de cirurgias, 15\% eram politraumatizados, $15 \%$ foram internados na UTI devido a infarto agudo do miocárdio e $20 \%$ de causas variadas, como, crise asmática, doença pulmonar obstrutiva crônica, contusão pulmonar, pancreatite e hemorragia digestiva.

Em relação à questão aberta: Você esteve internado na UTI e soube que foi cuidado por alunos de enfermagem. Fale para mim o que significou para o Sr. (Sra.) receber os cuidados por alunos da enfermagem quando esteve internado na UTI? Obtiveram-se as seguintes ideias centrais:
Quadro 1 - Ideias centrais, respondentes e frequência das ideias centrais.

\begin{tabular}{|l|l|l|l|}
\hline $\mathrm{N}^{\circ}$ & Ideias centrais & \multicolumn{1}{|c|}{ Respondentes } & Frequência \% \\
\hline 1 & $\begin{array}{l}\text { Fui bem cuida- } \\
\text { do e bem tra- } \\
\text { tado e não fez } \\
\text { diferença por } \\
\text { serem alunos. } \\
6,7,8,4,5,10, \\
13,15,16,18, \\
19,20\end{array}$ & 16 \\
\hline 2 & $\begin{array}{l}\text { Senti segurança, } \\
\text { confiança e fui } \\
\text { respeitado. }\end{array}$ & $\begin{array}{l}1,7,13,14, \\
17\end{array}$ & 5 \\
\hline 3 & $\begin{array}{l}\text { Melhorou muito } \\
\text { os cuidados. }\end{array}$ & $9,11,12,17$ & 4 \\
\hline 4 & $\begin{array}{l}\text { Diminuiu a } \\
\text { solidão. }\end{array}$ & 7 & 1 \\
\hline
\end{tabular}

\section{Discussão}

Referente a idéia central Fui bem cuidado e bem tratado e não fez diferença por serem alunos percebe-se que a dedicação, a presença constante, a proximidade e a interação da equipe de enfermagem são facilitadores para uma adequada adaptação e aceitação do paciente durante a internação na UTI. $\mathrm{O}$ ato de cuidar implica em afeto, sensibilidade, solidariedade, compaixão e doação [9]. Esta sensibilidade requer o envolvimento humanístico do profissional, no qual o cuidado constitui a essência do saber e do fazer da enfermagem [10]. O acadêmico de enfermagem ao prestar assistência ao paciente internado na UTI sente a necessidade de um cuidar mais sensível onde exista o uso da tecnologia em sintonia com todas as necessidades do paciente [11].

No DSC abaixo ficou evidente que os pacientes foram capazes de perceber a presença e a atuação do acadêmico de enfermagem durante o período que estiveram internados na UTI.

"Fui muito bem cuidada pelos alunos de enfermagem, cuidaram de mim com muito carinho, atenção e paciência. Eles são muito tranquilos enquanto cuidam de nós e fazem tudo direitinho. Sáo acessíveis, tem muita vontade em fazer aquilo que fazem. Cheguei a perguntar se eles realmente gostavam daquilo que eles faziam e disseram que gostavam muito de cuidar dos pacientes. (...) Percebi que eles querem muito aprender e também são muito competentes naquilo que estão fazendo. (...) Para falar a verdade nem 
dava para perceber que eram alunos que estavam aprendendo porque $o$ atendimento era tão bom quanto dos outros funcionários que trabalham na UTI. (...) Vi que eles tinham dom para cuidar, os alunos até parecem que já são formados. (...) Gostei muito dos cuidados que recebi, não tenho nada do que reclamar. Fui muito bem cuidado na UTI tanto que eu não queria sair de lá. Eles merecem nota dez. Eles tratam a gente muito bem, cuidam direitinho, gostei muito de lá, foi perfeito. Os alunos são gente boa, alegres e me trataram muito bem."

É importante perceber que os pacientes conseguiram identificar no cuidado prestado pelo acadêmico de enfermagem sentimentos como carinho, paciência e alegria no cuidar. Reconheceram a dedicaçáo e a qualidade dos cuidados recebidos. Deve ser destacado que pelo fato do paciente ter todas as suas necessidades atendidas adequadamente ele náo conseguiu diferenciar o cuidar do acadêmico em relação ao do profissional de enfermagem da unidade de terapia intensiva.

Em relação a ideia central Senti segurança, confiança e fui respeitado percebe-se que no processo do cuidar existem condiçóes que são fundamentais como a disponibilidade, a receptividade, e a confiança, o que gera crescimento tanto daquele que cuida quanto do ser que é cuidado [12].

Algumas atitudes da equipe de enfermagem como atitudes que demonstram segurança, conhecimento técnico-científico, paciência e respeito facilitam a relação do profissional com o paciente. Se houver empatia e compromisso do profissional para com o paciente será mais fácil a criaçáo de um vínculo de confiança [13].

No DSC abaixo ficou claro que é necessário que seja criado um vínculo de confiança entre o paciente e aquele que presta o cuidado.

"Me senti seguro, não tive nenhum medo de ser cuidado pelos alunos. Fui bem cuidado e respeitado. Eles não tem nojo da gente que é mais velho e isto é importante. Não tinham nojo para cuidar mesmo quando o paciente estava soltando as coisas como fezes e vômito. Não tinham medo de colocar a mão no paciente, não faziam cara feia. Eu vi que eles respeitam, cuidam com carinho e tem verdadeiro dom naquilo que fazem.
Me senti confiante, quando tinha alguma emergência eles chamavam a professora que atendia rapidamente e muito bem e isto dava muita segurança para a gente. Eles respeitam muito os pacientes e isto é primordial."

Para que ocorra uma verdadeira interação entre aquele que é cuidado e aquele que cuida é necessário que exista confiança e respeito. As atitudes adequadas e coerentes demonstradas pelos acadêmicos, aliadas à presença constante do professor, permitiram que o paciente desenvolvesse sentimentos de confiança e segurança nas açôes realizadas pelos acadêmicos. $\mathrm{O}$ estabelecimento da relação ajuda-confiança fez com que se sentissem também totalmente respeitados.

Quanto à ideia central Melhorou muito os cuidados, não foram encontradas nas referências acessadas quem discorresse sobre o assunto na íntegra das ideias abordadas. Acreditamos que a abordagem possa ser direcionada para o cuidado humanístico baseado na Teoria do Cuidado Transpessoal quando coloca que a tecnologia é imprescindível nas instituições hospitalares, mas que esta não pode sobrepor às necessidades da pessoa. $\mathrm{O}$ importante é atrelar o cuidado de forma a atendê-la como ser bio-psico-sócio-espiritual [14].

Tal colocação reflete a filosofia da EEWB e dos docentes quando conduzem seus acadêmicos à conscientização da necessidade de um cuidado holístico. Este quando este é pautado em uma filosofia humanística e utiliza de valores como empatia, sensibilidade, solidariedade e compreensão é capaz de minimizar o sofrimento gerando deste modo um cuidado diferenciado [15].

“(...) Vi que eles cuidam melhor do que muitos que já são formados e são mais velhos. Senti uma diferença muito grande quando os alunos chegaram porque eles me deram muita atenção, não deixaram me faltar nada. Os alunos são excelentes foi muito melhor ser cuidado por eles. Eles são muito educados, não desprezam a gente e são todos muito bons. Senti firmeza nos alunos, eles são muito especiais até parece que foi Deus que enviou eles para cuidar de mim e isto ajudou muito na minha recuperação. Para mim eles cuidam até melhor e com mais atenção do que os funcionários que trabalham lá, apesar de que todos cuidaram muito bem de mim. A ajuda dos alunos é muito importante e 
melhora muito o cuidado que nós recebemos e eu sou muito agradecido por tudo o que eles fizeram por mim.”

Ao analisar o discurso percebe-se que o paciente, mesmo estando diante de uma situação crítica como é a internaçáo na unidade de terapia intensiva, conseguiu claramente perceber que o acadêmico tinha algo a mais e foi considerado especial como se fosse um presente divino.

Relativo à ideia central Diminuiu a solidão, percebe-se a internação na UTI é uma situação ameaçadora, pois representa para o paciente o afastamento do seu lar, a separação de seus familiares e entes queridos [16]. É necessário o conhecimento dos fatores estressores para o paciente internado na UTI, objetivando um melhor planejamento da assistência, com a finalidade de facilitar a sua recuperação e promoção de um ambiente mais humanizado [17].

"Na UTI a gente fica muito sozinho e quando os alunos estão lá a gente conversa com todos, porque eles são muito atenciosos e cuidadosos (...). Além de cuidarem eles conversavam muito comigo e isto ajudou a diminuir a solidão que eu estava sentindo. Teve um dia no horário de visita que ninguém da minha família veio me ver porque eles não moram aqui em Itajubá, os alunos viram que eu fiquei triste e deixaram de sair para lanchar para me fazerem companhia, tanto que eu nem vi a hora passar e quando percebi já tinha passado o horário de visita."

O ambiente da UTI representa uma ameaça para o paciente a partir do momento em que ele se encontra doente e se vê subitamente afastado do convívio familiar. Diante desta situação percebeu-se nitidamente que a presença do acadêmico foi significativa para o paciente a partir do momento em que ele foi capaz de perceber não apenas o sofrimento físico. A solidão é considerada um estressor psicológico que necessita de intervenções que proporcionem uma melhor adaptação do paciente ao ambiente da UTI [18].

A enfermagem é uma profissão que vislumbra o bem estar da pessoa no seu modo de ser e que necessita de atitudes concretas para prestar uma assistência efetiva [19].

Neste estudo em relação aos significados para o paciente egresso da UTI e que recebeu assistência dos acadêmicos de enfermagem neste período foram: Fui bem cuidado e bem tratado e não fez diferença por serem alunos; Senti segurança, confiança e fui respeitado; Melhorou muito os cuidados e Diminuiu a solidão.

Os dados obtidos com o estudo revelam que todos os pacientes reconheceram a dedicação e a qualidade da assistência prestada pelo acadêmico de enfermagem.

\section{Conclusão}

$\mathrm{O}$ acadêmico de enfermagem na UTI enfrenta dificuldades no desenvolvimento de suas atribuiçóes devido ao posicionamento, muitas vezes, inadequado de profissionais que fazem colocaçóes que podem até mesmo denegrir a imagem do docente e do acadêmico, afastando-os desta unidade. Apesar destas colocaçóes ficou claro que a assistência prestada pelo acadêmico, sob o olhar do paciente foi benéfica, transmitiu segurança, confiança, amenizou a solidão e criou uma relaçáo de ajuda-confiança a partir do respeito estabelecido.

Não houve relato com conotação negativa quanto aos cuidados prestados pelos acadêmicos, o que tranquiliza os docentes e os acadêmicos quanto aos seus papéis em um ambiente que exige, além de competência técnica, a capacidade de ir ao encontro do outro, atendendo-o no mais íntimo de seu ser.

A humanização e o acolhimento devem ocorrer tanto para o paciente quanto para os familiares, pois ao ser internado na UTI o paciente náo perde a sua essência ou a sua cidadania. Ele continua sendo um Ser que, embora esteja temporariamente afastado do seu contexto familiar, necessita do apoio e da presença da família na sua recuperação.

Outro aspecto que merece ser destacado são as atitudes, a postura, a interação e a comunicação do acadêmico ao prestar os cuidados. O processo de comunicaçáo entre o profissional de saúde e o paciente deve ser eficiente para viabilizar um cuidado humanizado que atenda as necessidades da pessoa atendida.

A atuação do docente também foi percebida como essencial pelo fato deste profissional ser o facilitador do processo ensino-aprendizagem e o mediador do acadêmico junto aos pacientes internados na UTI.

A Escola de Enfermagem Wenceslau Braz preocupada com a formaçáo de alto nível dos seus 
acadêmicos cumpre o seu papel evidenciado pelos relatos dos participantes do estudo no que se refere à qualidade da assistência prestada pelo acadêmico sempre sob a orientação, acompanhamento e supervisão do docente.

A atuação do acadêmico nas instituições de saúde, e em especial na UTI, além de contribuir imensamente para a assistência de enfermagem contribui também para o enriquecimento profissional daqueles que nela atuam em vista que oportuniza a troca de conhecimentos e experiências.

\section{Referências}

1. Couto RC. Ratton Emergências médicas e Terapia Intensiva. Rio de Janeiro: Guanabara Koogan; 2005.

2. Santos I, Figueiredo NMA, Padilha MICS, Cupello AJ, Souza SROS, Machado WCA. Enfermagem assistencial no ambiente hospitalar - realidade - questóes - soluçóes. Série Atualizaçóes em Enfermagem. São Paulo: Atheneu; 2005.

3. Martins JT, Robazzi MLCC, Marziale MHP, Garanhani ML, Haddad MCL. Significados do Gerenciamento de Unidade de Terapia Intensiva para o enfermeiro. Rev Gaúch Enferm 2009;30(1):113-9.

4. Silva CG, Oliveira MH, Matias RC. Paciente alcoolista: sentimentos dos profissionais de enfermagem [TCC]. Itajubá: Escola de Enfermagem Wenceslau Braz; 2008.

5. Brevidelli MM, Domenico EBL. Guia prático para docente e alunos da área da saúde [TCC] São Paulo: Iátria; 2006.

6. Polit DF, Beck CT, Hungler BP. Fundamentos de Pesquisa em Enfermagem: métodos, avaliação e utilização, 5a. ed. Porto Alegre: Artmed; 2004.

7. Moscovici S. Representaçôes sociais da psicanálise. Rio de Janeiro: Zahar; 1978.
8. Lefrévre F, Lefrévre AMC. O discurso do sujeito coletivo: Um novo enfoque em pesquisa qualitativa (desdobramentos). Caxias do Sul: Educs; 2003.

9. Pina RZ, Lapchinsk LF, Pupulim JSL. Percepção de pacientes sobre o período de internação em unidade de terapia intensiva. Ciências Cuidados Saúde 2008;7(4):503-8.

10. Moura KS, Araújo LM, Araújo LM, Valença CN, Germano RM. A vivência do enfermeiro em terapia intensiva: estudo fenomenológico. Rev RENE 2011;12(2):316-23.

11. Santana JCB. Avanços tecnológicos e os limites dentro de uma Unidade de Terapia Intensiva no processo ético do cuidar: significado para os acadêmicos de enfermagem. Centro Universitário São Camilo 2008;2(1):73-80

12. Lima JOR, Munari DB, Esperidiáo E, Souza JC. Aprendendo o cuidado humanizado: a perspectiva do graduando de enfermagem. Ciência, Cuidado Saúde 2007;6(1):11-20.

13. Severo GC, Perlini NMOG. Estar internado em Unidade de Terapia Intensiva: percepção de pacientes. Scientia Medica 2005;15(1):21-9.

14. Watson J. Nursing the philosophy and science of caring. Boulder: Associated University Press; 1985.

15. Sales LVT, Paixão MG, Castro O. In: Teorias de Enfermagem. $1^{a}$. ed. São Paulo: Iátria; 2011.

16. Stumm EMF, Kuhn DT, Hildegrandt LM, Kirchner RM. Estressores vivenciados por pacientes em uma UTI. Cogitar Enferm 2008;13(4):499-506.

17. Proença MO, Agnolo CMD. Internação em unidade de terapia intensiva: percepçáo de pacientes. Rev Gaúch Enferm 2011;32(2):279-86.

18. Rosa BA, Rodrigues RCM, Gallani MCBJ, Spana TM, Pereira CGS. Estressores em Unidade de Terapia Intensiva: versão brasileira do The Environmental Stressor Questionnaire. Rev Esc Enferm USP 2010;44(3)627-35.

19. Campos LF, Melo MRAC. Assistência em enfermagem na perspectiva da clínica ampliada em unidade de terapia intensiva. Rev Gaúcha Enferm 2011;32(1):189-93. 